\title{
Tree Volume Equation for Populus deltoides (Poplar) Tree under Agroforestry Based
}

\author{
S.A. Aminu*, Sameer Daniel and I. Yakubu \\ College of Forestry, Sam Higging bottom University of Agriculture Science \\ and Technology Allahabad, India \\ *Corresponding author
}

\begin{tabular}{|l|}
\hline Ke y w o r d s \\
$\begin{array}{l}\text { Populus deltoids, } \\
\text { Agroforestry, } \\
\text { Volume Equation, } \\
\text { Merchantable } \\
\text { Volume }\end{array}$ \\
\hline Article Info \\
\hline $\begin{array}{l}\text { Accepted: } \\
\text { 12 January } 2019 \\
\text { Available Online: } \\
\text { 10 February } 2019\end{array}$ \\
\hline
\end{tabular}

A B S T R A C T

Trees are the most important component of Agroforestry, they provide, shelter, food, nutrient for soil and fodder for animals. Poplar trees have an important commercial value and can make an important contribution to the economy of the country. Tree volume equations were developed for prediction and estimation of merchantable volume. Data were collected with the aid of haga altimeter, meter tape and calliper. The measurement obtain were the diameter at breast height (D.B.H), diameter at base, diameter at top and merchantable height. Merchantable volume was calculated with the aid Newton's formula. Data collected were subjected to Microsoft excel and using Statistical Package for the Social Scientists (SSPS) for statistical analysis. Eight linear and non linear (logarithmic) models were developed for estimation prediction of tree merchantable volume. The models developed were fitted to the data for each of the species. Coefficient of determination $\left(\mathrm{R}^{2}\right)$ ranged from 77 to $99 \%$. The statistical indices indicated that the resulting models possessed all the statistical assumption. The Schumacher-Hall's volume was rated the best among the eight developed models. The resulting equation were tested for validation with data collected from different location and it was discovered that the models did not violet the statistical assumption. This suggests that the models are desirable for merchantable volume estimation in the study area.

\section{Introduction}

Agroforestry is a general term for different methods of integrating crops or livestock together with tree species into a system. The practice of combining trees with crops has proven to bring great environmental benefits, such as increasing the local sequestration of Carbon and supporting ecosystem services (Nair et al., 2009). Agroforestry can also provide social benefits since it can supply many of the household needs such as food and firewood etc. It can also distribute income throughout the year with multiple harvests and reduce seasonal labour peaks (Murthy et al., 2013). The great diversity of species in agroforestry makes is possible to harvest at several times throughout the year. This evens out the labour peaks during the year as well as the income. The financial resilience will also increase because of the reduced vulnerability of total crop failure, which is more common 
in single-cropping or monoculture practices (Kumar, 2016; Murthy et al., 2013). The soil improving properties of agroforestry are also very likely to increase the total productivity of the land, resulting in greater income for the farmer (Murthy et al., 2013). The systems can also act as an investment, by planting timber species such as poplar and teak.

Poplar is among the world's fast growing industrial softwood species. Their deciduous nature and slender crown permits the inter cultivation of a variety of seasonal and annual crops. However, poplar being sensitive to water logging, can check the traditional vicious cycle of rice-wheat systems in the region (Rani et al., 2011). Poplar mostly occurs in low-lying, moist alluvial ground, and tolerates flooding for a short time during the rainy season, and can be propagated vegetatively (Lodhiyal et al., 1994)

Timber volume is an important ecological component in forested landscapes. Timber volume determination is a key element in the wood products supply chain and in sustainable forest management. One limitation to estimating volume is the lack of an efficient, accurate, and objective methodology (Yuan, 2015). Efficient management of timber resources depends on accurate volume assessments of forest stands. The goal of timber management is to provide the mix of timber quality, quantity and size that will maximize owner satisfaction while resolving imposed constraints (Newberry, 1984). Consequently, accurate and flexible methods are required to estimate stand and tree growth and yield for evaluating the numerous management and utilization alternatives for timber resources (Sharma et al., 2000). Managing of forest tree stands require volume equations. Sustainable utilization of timber requires an inventory of the stock hence the need for developing tree volume equations that can be use for estimating timber volume. However the study aimed at developing tree volume models that can be used for the poplar tree species in the study area.

\section{Materials and Methods}

\section{Study area}

The research was conducted within environment of Sam Higg in bottom University of Agriculture, Technology and sciences which is located within Allahabad City UP. Allahabad posses` tropical to subtropical climate with extreme summer and winter on an average of rainfall of $110 \mathrm{~mm}$ most of which is concentration during monsoon season, the temperature falls to as low as $5^{0}$ in winter which in summer it reaches above $45^{\circ}$. Hot sizzling winds are quite common during summer and sporadic spell of frost during the winter.

\section{Data collection}

Data were collected through non destructive procedure with the use of Haga altimeter, calliper, and meter tape. The data consisted of the diameter at breast height D.B.H $(1.3 \mathrm{~m}$ above ground), middle, top and merchantable height. Disease and death tress will be excluded in the study.

\section{Data analysis}

Data collected were transfer to Microsoft excel for computation and manipulations. Newton's formula was used in computing the Volume of the tree. The formula requires the use of tree height and diameter at three different levels along the stem. Measuring tree diameter at these points ensures that tree form is taken into consideration, and this makes the Newton's formula more accurate than other common formulas such as Huber's and Smalian's formulas (Avery and Burkhart, 
2002). According to (Husch et al., 2003), Newton's formula is expressed as:

$v=\frac{\pi H}{24}\left(D_{b}^{2}+4 D_{m}^{2}+D_{t}^{2}\right)$ 5

Where:

$\mathrm{V}=$ Tree Volume $\left(\mathrm{m}^{3}\right) ; \mathrm{H}=$ Tree height $(\mathrm{m})$; and $\mathrm{Db}, \mathrm{Dm}$, and $\mathrm{Dt}$ are tree diameters at base $(45 \mathrm{~cm}$ above ground level), middle and top positions $(7 \mathrm{~cm}$ upper limit diameter), respectively. All diameters collected in centimetre will be converted to meter before applying the formula. Descriptive statistics will be conducted to obtain the description of the data of the study.

\section{Volume Model Generation}

Regression analysis was conducted to create a Linear and non linear models relating to tree volume as the dependent variable to Diameter at breast height and merchantable height as the independent variable. The models will be evaluated for their quality and fit in the analysis Parameters of the functions will be estimated using Statistical Package for the Social Scientists (SPSS) version 16. The general linear regression model has the formula:

$Y_{i}=\beta_{0}+\beta_{1} X_{1 i}+\beta_{2} X_{2 i}+---\varepsilon_{i}$

Where

$\mathbf{Y}=$ dependent variable;

$\mathrm{X}=$ independent variable;

$\beta=$ regression parameters;

$\varepsilon=$ variation not explained by the regression model (error term).

The Linear and non linear model to be tested are:

$v=\beta=+\beta_{1} D$

$v=\beta s+\beta_{1} D^{2}$

$$
\begin{aligned}
& v=\beta_{0}+\beta_{1} D^{2} H \\
& v=\beta_{s}+\beta_{1} D^{2}+\beta_{2} H \\
& V=\beta_{s}+\beta_{1} D+\beta_{2} D H+\beta_{3} H \\
& \ln v=\beta_{0}+\beta_{1} \ln D^{2} H \\
& \ln v=\beta_{s}+\ln \beta_{1} D^{2}+\ln \beta_{2} H \\
& \ln V=\beta_{s}+\ln \beta_{1} D+\ln \beta_{2} D H+\ln \beta_{3} H
\end{aligned}
$$

Where:

$\mathrm{V}=$ Tree volume $\left(\mathrm{m}^{3}\right), \mathrm{H}=$ tree height $(\mathrm{m})$, $\mathrm{D}^{2} \mathrm{H}=$ dbh square and height, ${ }^{l n}=$ Natural $\log$ $\beta_{0}$ and $\beta_{1}$ are the parameters of the function.

\section{Results and Discussion}

The results indicated that the mean height of the trees was $11.93 \mathrm{~m}$ with standard deviation of 3.38; mean diameter at breast height (D.B.H) was $0.25 \mathrm{~m}$ while the standard deviation was 0.08 . The mean merchantable volume was $0.37 \mathrm{~m}^{3}$ in the study area. The results from table 1 below indicated that all the tree growth variables in the study area have low standard deviation hence the validity of the data set. The trees in the study area follow similar trend in tapering from bottom to the top; this agrees with study conducted by Shamaki, et al, 2011. This confirms the biological validity of the data set as indicated by Husch et al., (2003).

\section{The volume equation}

To check the relationship between the tree variables (DBH, height and volume), correlation analysis was conducted and the result revealed that there is positive relationship between the tree growth variables in the study area; this shows that the independent variables can be used for developing tree volume equation. This agrees with the study conducted by Shamaki et al, 2011. Although Akindele and LeMay (2005) found the relationship between height and 
volume as weak and positive and did not show any meaningful trend, which were attributed to the variability of the Crown Point for measuring upper limit merchantable height between and within species. Shamaki, further stated that Using height in the volume equation generally provides a better estimate as it helps account for soil, climate and some cultural variations (thinning, weeding and pruning at regular intervals). In this study, volume equation was developed using Dbh and height as independent variables to estimate merchantable volume. The table 2 below shows the result of correlation analysis between the tree variables.

Table.1 Distribution of DBH, height and volume

\begin{tabular}{|l|l|l|l|l|l|}
\hline Tree Variables $(\mathbf{m})$ & Observations & Mean & Std. Dev. & Min & Max \\
\hline Merchantable Height & 86 & 11.93 & 3.48 & 2.20 & 19.8 \\
\hline DBH at Middle & 86 & 0.25 & 0.08 & 0.08 & 0.43 \\
\hline DBH at Base & 86 & 0.27 & 0.09 & 0.09 & 0.47 \\
\hline DBH at Top & 86 & 0.25 & 0.08 & 0.07 & 0.42 \\
\hline $\begin{array}{l}\text { Merchantable Volume } \\
\left(\mathbf{m}^{\mathbf{3}}\right)\end{array}$ & 86 & 0.37 & 0.29 & 0.02 & 1.41 \\
\hline
\end{tabular}

Table.2 Coefficients of correlation between the variables for poplar

\begin{tabular}{|l|l|}
\hline Variables & Correlation coefficient \\
\hline Height vs. volume & 0.386 \\
\hline Dbh vs. height & 0.879 \\
\hline Height vs. volume & 0.671 \\
\hline
\end{tabular}

Table.3 Multiple volume equations generated for poplar

\begin{tabular}{|l|l|l|l|l|}
\hline s/no & Equations & $\begin{array}{l}\text { Adjusted } \\
\mathbf{R}^{\mathbf{2}}\end{array}$ & $\mathbf{S E E}$ & Rank \\
\hline $\mathbf{1}$ & $\mathrm{V}=-0.411+0.879 \mathrm{D}$ & 0.770 & 0.141 & $8^{\text {th }}$ \\
\hline $\mathbf{2}$ & $\mathrm{V}=-.0641759+0.915 \mathrm{D}^{2}$ & 0.836 & 0.119 & $7^{\text {th }}$ \\
\hline $\mathbf{3}$ & $\mathrm{V}=0.005+0.998 \mathrm{D}^{2} \mathrm{H}$ & 0.995 & 0.021 & $3^{\text {rd }}$ \\
\hline $\mathbf{4}$ & $\mathrm{V}=-0.0353+0.770 \mathrm{D}^{2}+0.356 \mathrm{H}$ & 0.942 & 0.071 & $6^{\text {th }}$ \\
\hline $\mathbf{5}$ & $\mathrm{V}=0.1044+-0.5735 \mathrm{D}+0.2498 \mathrm{DH}+-0.0312 \mathrm{H}$ & 0.977 & 0.045 & $4^{\text {th }}$ \\
\hline $\mathbf{6}$ & $\mathrm{LnV}=-0.8967+0.9816 \mathrm{LnD}^{2} \mathrm{H}$ & 0.996 & 0.056 & $1 \mathrm{st}$ \\
\hline $\mathbf{7}$ & $\mathrm{LnV}=-0.9874+0.9608 \mathrm{LnD}^{2}+1.0005 \mathrm{LnH}$ & 0.988 & 0.105 & $5^{\text {th }}$ \\
\hline $\mathbf{8}$ & $\mathrm{LnV}=-0.9259+0.2921 \mathrm{D}+1.6771 \mathrm{LnDH}+-0.6799 \mathrm{LnH}$ & 0.996 & 0.056 & $1^{\text {st }}$ \\
\hline
\end{tabular}

Eight (8) different volume equations were developed using regression analysis for estimating merchantable volume which were in the form of linear and log-transformed form (also termed Schumacher's volume function). The coefficient of determination $\left(\mathrm{R}^{2}\right)$ and standard error of estimate (SEE) were all presented in the table 3. The coefficient of determination $\left(\mathrm{R}^{2}\right)$ ranged from $77 \%$ to $99 \%$ which indicated that large 
proportion of the variation in the tree volume was explained by $\mathrm{DBH}$ and height of the trees. Although equation six (6) and seven (7) had the highest $\mathrm{R}^{2}$ value (99\%) which is in log-transformed form while equation one (1) had the lowest $\mathrm{R}^{2}$ value (77) which is in linear form. This could be attributed to the assumption that Dbh and height are two different independent variables and combining them together in an equation may need some transformation of the original data as confirmed by Akindele and LeMay (2005). According to Husch et al., (2003), logarithmic transformation of DBH and height is used to equalize the variation about the regression line and linearize a non-linear function. Another index for checking goodness of fit is the Root mean square error (RMSE) and standard error of estimate (SEE). RMSE and SEE are good measures of how accurately the model predicts the response, and it is the most important criterion for fit if the main purpose of the model is prediction; Lower value of RMSE and SEE indicates better fit. The SEE values for this species ranged from $0.141 \mathrm{~m}^{3}$ to $0.105 \mathrm{~m}^{3}$. The SEE calculated was low and this suggests good fit. The results are presented in table 3 .

The study generated eight volume equations for prediction and estimation of tree merchantable volume in the study area. A total of 86 polar trees were used to develop the volume equations. Finding from the study indicated that the standard deviation of all the data collected from both the two trees species were very small which means there was not much deviation from the average. There was high correlation between the dependent and independent variables. The generalized logarithmic volume function (also termed Schumacher's volume function) performed better than other linear forms of volume functions. The same models were used for data collected from different location for validation and it was discovered the models have all the statistical goodness of fit. The tree volume equations developed for this study appeared to be very precise. The residual analysis was distributed below and above zero. This indicated goodness of fit of the models. It is therefore concluded that the models are efficient for prediction of merchantable volume of poplar in the study area.

\section{References}

Avery, T. E. and H. E. Burkhart (2002). Forest Measurements. 5th Edition. McGraw-Hill Higher Education, New York. 456p.

Avery, T.E. and H.E. Burkhart. 1994. Forest measurement. 4th ed. McGraw Hill Book Co., New York. 408pp.

Huang, S., Y. Yang and Y. Wang (2003). A critical look at procedures for validating growth and yield models. In: Amaro, A., D. Reed and P. Soares (Eds.). Modeling Forest Systems. $\mathrm{CAB}$ International, Vancouver, Canada. pp156-172.

Husch, B., T. W. Beers and J. A. Kershaw Jr. (2003). Forest Mensuration. 4th edition. John Wiley and Sons Inc., New Jersey. 443p.

Akindele S.O. and LeMay V.M. (2006). Development of Tree Volume Equations for Common Timber Species in the Tropical Rainforest Area of Nigeria Forest Ecology and Management, 226: 41-48.

Newberry, J. D. (1984). Methods for modeling whole stem diameter growth and taper. A Ph.D. Thesis. Virginia Polytechnic Institute and State University, Blacks, VA.

S. Rani, S.K. Chauhan, R. Kumar and K.K. Dhatt (2011). Bioeconomic Appraisal of Flowering Annuals for Seed Production under Poplar (Populus deltoides) Based Agroforestry System 
Tropical Agricultural Research Vol. 22 (2): $125-133$.

Yuan Sun, Xinlian Liang, Ziyu Liang, Clive Welham and Weizheng LI (2015). Deriving Merchantable Volume in Poplar through a Localized Tapering Function from Non-Destructive Terrestrial Laser Scanning: forests, 7(87).

Nair, P.K.R., Nair, V. D., Kumar, B. M., \& Haile, S. G. (2009). Soil carbon sequestration in tropical agroforestry systems: A feasibility appraisal. Environmental Science and Policy, 12(8), 1099-1111. doi: 10.1016/j.envsci.2009.01.010.

Kumar, V. (2016) Universal Agroforestry Systems in Tropics Region- a review.
Nature Environment and Pollution Technology 15(2) ISSN: 0972-6268. Murthy, I.K., Gupta, M., Tomar, S., Munsi, M., Tiwari, R., Hegde, G.T. and Ravindranath, N.H (2013) Carbon Sequestration Potential of Agroforestry Systems in India. Journal of Earth Science and Climate Change, Volume 4(1) doi: 10.4172/21577617.1000131

S. B. Shamaki, S. O. Akindele and A. D. Isah (2011): Development of Volume Equations For Teak Plantation In Nimbia Forest Reserve In Nigeria Using Dbh And Height Journal of Agriculture and Environment Vol. 7 No. 1, June 2011: 71-76

\section{How to cite this article:}

Aminu, S.A., Sameer Daniel and Yakubu, I. 2019. Tree Volume Equation for Populus deltoides (Poplar) Tree under Agroforestry Based. Int.J.Curr.Microbiol.App.Sci. 8(02): 14701475. doi: https://doi.org/10.20546/ijcmas.2019.802.170 